\title{
Situação vacinal de crianças menores de um ano na Estratégia de Saúde da Família de Campo Limpo III em Feira de Santana/BA
}

\author{
Shirly Nascimento Rodrigues Costa*, Luciana Mascarenhas Silva*, Kariane Barbosa Almeida Freire**
}

${ }^{*}$ Enfermeiras graduadas pela Faculdade Anisio Teixeira - FAT, Feira de Santana/BA, **Enfermeira, Especialista de Gestão em Saúde pela Faculdade de Tecnologia e Ciências/FTC, Especialista em Enfermagem do Trabalho pela Faculdade Tecnologia Internacional/FTI, Coordenadora da Atenção Básica do Município de Santa Barbara/BA

\begin{abstract}
Resumo
Objetivo: Identificar o estado vacinal de crianças menores de 01 ano que frequentam a Estratégia de Saúde da Família de Campo Limpo III em Feira de Santana/BA. Método: Pesquisa com abordagem quantitativa de caráter exploratório, realizada em 68 cartôes controle e 68 cartóes sombras dos Agentes Comunitários de Saúde de crianças menores de um ano acompanhadas pela unidade de saúde, de acordo com dados do Sistema de Informação da Atenção Básica, no ano de 2010. A análise foi realizada com base na observaçấo das doses, intervalos das vacinas específicas para cada idade como preconiza o Programa Nacional de Imunização (PNI). Resultados: O estudo revela que nenhuma das vacinas estudadas atingiu a meta estabelecida pelo PNI. A cobertura vacinal foi de $72 \%$, apenas a vacina BCG aproximou-se da meta estabelecida pelo PNI. Conclusão: Vacinas dadas nos primeiros meses de vida apresentaram maior cobertura vacinal. O estudo permitiu mensurar o grau de crianças suscetíveis a doenças imunopreviníveis e os cuidados que a equipe de saúde precisa ter em relação a essas crianças.
\end{abstract}

Palavras-chave: criança, idade, imunização, vacinas, saúde.

\begin{abstract}
Immunization status of children under 1 year old in Family Health Strategy of Campo Limpo III in Feira de Santana/BA

Objective: To identify the immunization status of children under 1 year old attended Family Health Strategy Unit of Campo Limpo III in Feira de Santana/BA. Method: This quantitative and exploratory study was carried out with 68 immunization record cards and 68 immunization tracking cards of Community Health Workers of children under one year who are attending the health unit, according to Primary Care Information System data in 2010. The analysis was based on observation of vaccine dose, intervals of specific vaccines for each age as recommended by the National Immunization Program (NIP). Results: The study reveals that none of the vaccines studied reached the target set by the NIP. Vaccination coverage was $72 \%$, only BCG approached the target set by the NIP. Conclusion: Vaccines administered in first days of life had higher immunization coverage. The study allowed us to know the level of immunopreventable diseases in children and the special care that health care team should offer to these children.
\end{abstract}

Key-words: child, age, immunization, vaccines, health. 


\section{Resumen}

\section{Cobertura de vacunación en niños menores de 01 ano en Estrategia Salud de la Familia de Campo Limpo III en Feira de Santana/BA}

Objetivo: Identificar la cobertura de inmunización en nińos menores de 01 año que frecuentan la Estrategia de Salud de la Familia de Campo Limpo III en Feira de Santana/BA. Método: Se trata de una investigación cuantitativa-exploratoria que fue realizada con 68 tarjetas de control de inmunización y 68 tarjetas de control "duplicado" de Trabajadores de Salud Comunitaria de niños menores de un año atendidos en la unidad de salud, de acuerdo con datos del Sistema de Información de Atención Primaria en el año 2010. El análisis fue realizado con bases en la observación de las dosis e intervalos de vacunas específicos para cada edad según lo recomendado por el Programa Nacional de Inmunización (PNI). Resultados: El estudio revela que ninguna de las vacunas estudiadas alcanzó el objetivo establecido por el PNI. La cobertura de vacunación fue del 72\%, sólo BCG se acercó a la meta establecida en el PNI. Conclusión: Las vacunas administradas en los primeros meses de vida alcanzaron mayor cobertura de inmunización. El estudio permitió calcular la vulnerabilidad de enfermedades inmunoprevenibles en niños y la atención que el equipo de salud debe tener en relación a estos niños.

Palabras-clave: niño, la edad, la inmunización, vacunas, salud.

\section{Introdução}

As vacinas são fundamentais para prevenir um grande número de doenças infectocontagiosas e suas possíveis consequências. É necessário orientar e educar devidamente a família quanto à importância dos imunobiológicos, além dos riscos de não se cumprir o calendário vacinal [1].

O Programa Nacional de Imunização (PNI) foi criado visando coordenar as estratégias de vacinação em todo território nacional e chegou a alcançar grandes avanços em termos de cobertura vacinal. Apesar de ser um programa de suma importância na área da imunização, o alcance das metas estipuladas pelo PNI ainda encontra dificuldades, tais como recursos insuficientes, difícil acesso por parte dos vacinadores em algumas áreas descobertas onde a equipe de saúde não atua, falta de disponibilidade dos pais, medo das reaçóes adversas e descaso de alguns profissionais de saúde [2].

O PNI foi formulado em 18 setembro 1973 pelo governo Federal e então Ministro da Saúde, Mario Machado de Lemos, com o objetivo de oferecer todas as vacinas com qualidade a toda a população, tentando alcançar a cobertura vacinal $100 \%$ de forma homogênea, coordenando as açóes e buscando a integridade da imunização ocorrida no país [3].

O PNI, na instância nacional, é de responsabilidade da Fundação Nacional de Saúde (FUNASA) do Ministério da Saúde. O desenvolvimento do programa é orientado por normas e técnicas estabelecidas nacionalmente, as quais se referem à conservação, ao transporte, à administração, à programação e à avaliação [4].
O suprimento dos imunobiológicos é de responsabilidade da instância federal que adquire o produto, coordena a importação e incentiva a produção nacional, o qual é distribuído pela Central Nacional de Armazenagem e Distribuição de Imunobiológicos, (CENADI) que por sua vez tem como competência receber, armazenar, acondicionar e distribuir os imunobiológicos [4].

A redução das doenças preveníveis por vacinação só será possível se os índices de cobertura vacinal forem atingidos e mantidos de forma homogênea, reduzindo, assim, a morbidade e mortalidade causadas por essas doenças, principalmente, em crianças de zero a doze meses [5].

Esta pesquisa teve como questão norteadora, a situação vacinal das crianças de zero a doze meses na Estratégia de Saúde da Família, Campo Limpo III no ano de 2010; tendo como objetivo, identificar o estado vacinal de crianças que frequentam o referido serviço de saúde, avaliar a real situação vacinal verificando o número de crianças faltosas à vacinação nesta faixa etária, bem como verificar o esquema vacinal preconizados no PNI, para que se possa subsidiar a unidade com os dados coletados.

\section{Material e métodos}

Estudo exploratório, pois visa proporcionar mais familiaridade com o problema a fim de torná-lo mais explícito. Neste sentido, o método que melhor se ajusta para a realização dessa pesquisa exploratória é o quantitativo. $\mathrm{O}$ método quantitativo permite mensurar um universo numericamente elevado, 
através de uma amostra que o represente de forma estatisticamente comprovada [6,7].

A pesquisa foi realizada na ESF de Campo Limpo III, que se caracteriza por um espaço de atendimento de promoção, proteção e prevenção aos agravos à saúde. A ESF Campo Limpo III corresponde à área urbana 027 , onde estão cadastradas 1.477 famílias, que correspondem a 5.729 pessoas, sendo 2.654 do sexo masculino e 3.075 do sexo feminino: desse total, 68 crianças são menores de 12 meses de acordo com dados do Sistema de Informação da Atenção Básica (SIAB), em abril de 2010.

Os dados foram coletados através dos seguintes documentos: cartão controle de vacinação da unidade e cartão sombra dos agentes comunitários de saúde. $\mathrm{O}$ estudo utilizou o esquema vacinal básico proposto pelo Ministério da Saúde para crianças de zero a doze meses. Vale salientar que as vacinas pneumocócica 10 e Meningocócica c conjugada, foram introduzidas no calendário básico de vacinação no ano desse estudo, respectivamente, a pneumocócica em 10 de março 2010 e meningocócica em agosto de 2010, por esse motivo náo fizeram parte das análises dos dados.

As análises dos documentos foram realizadas com base na observação das doses, intervalos das vacinas específicas para cada idade como preconiza o PNI. Os dados foram computados em uma planilha e analisados através de frequência absoluta e frequência relativa. Para a análise estatística, foi utilizada a fórmula de cobertura recomendada pelo Departamento de Informática do Sistema Único de Saúde (DATASUS) que verifica o número de doses aplicadas $\left(1^{\circ}, 2^{\circ}, 3^{\circ}\right.$ ou dose única) a depender da vacina, dividida pela quantidade de populaçáo estudada, multiplicada por 100, conforme pode ser visto abaixo:

$\mathrm{CV}=$ Crianças vacinadas do grupo etário com determinada vacina $X 100$

Número de crianças estudadas na faixa etária estabelecida
A pesquisa foi aprovada pelo Comitê de Ética em Pesquisa com seres humanos da Faculdade Adventista da Bahia (FADBA), protocolo no 0156.0.070.000-11 no ano de 2011 após autorização da Secretária Municipal de Saúde para a realizaçáo do estudo na Estratégia de Saúde da Família Campo Limpo III do município de Feira de Santana/BA.

\section{Resultados e discussão}

A situação vacinal das crianças de zero a doze meses no ano de 2010 no bairro Campo Limpo III na cidade de Feira de Santana/BA mostrou os resultados apresentados na Tabela $\mathrm{I}$.

Ao analisar os 68 cartóes-espelho e cartóes-sombra observou-se um índice de vacinação com esquema completo, não considerando a idade correta e intervalo correto de 72\%, (Gráfico 1), ou seja, das 68 crianças analisadas 49 estavam com o calendário vacinal completo independente da idade correta e do intervalo correto.

Gráfico 1 - Esquema vacinal de crianças menores de um ano na estratégia de saúde da família Campo Limpo III no município de feira de Santana BA no ano de 2010.

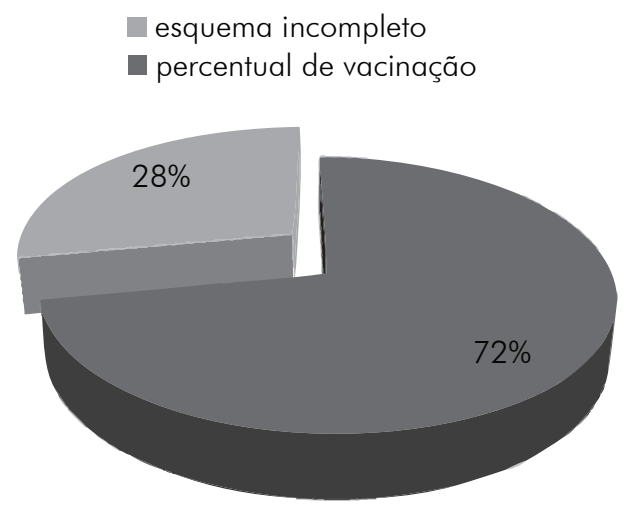

Tabela I - Situação vacinal de crianças de 0 a 1 ano na ESF Campo Limpo III no município de Feira de Santana/BA ano 2010

\begin{tabular}{lcccccccc}
\hline \multicolumn{1}{c}{ Vacinas } & Única & $\%$ & $1^{\circ}$ dose & $\%$ & $2^{\circ}$ dose & $\%$ & $3^{\circ}$ dose & $\%$ \\
\hline BCG & 61 & 89,71 & & & & & & \\
Hepatite B & & & 62 & 91,17 & 59 & 86,76 & 45 & 66,18 \\
Polio & & & 53 & 77,94 & 48 & 70,59 & 37 & 54,41 \\
Tetravalente & & & 55 & 80,88 & 47 & 69,12 & 36 & 52,94 \\
Rotavírus & & & 53 & 77,94 & 41 & 60,26 & & \\
F. amarela & & 34 & 50 & & & & \\
SRC & & 42 & 61,76 & & & & \\
\hline
\end{tabular}

Fonte: Pesquisa de campo, 2012. 
Considera-se a situação vacinal como a proporção de crianças vacinadas que receberam o esquema completo de vacinação preconizada pelo PNI na faixa etária estabelecida, cujas doses foram aplicadas na idade correta e com intervalos corretos. Assim, foram encontradas as coberturas apresentadas no Gráfico 2.

Gráfico 2 - Situação vacinal das crianças para as vacinas $B C G$, hepatite $B$, tetravalente, rotavírus, febre amarela, sarampo, rubeola, caxumba.

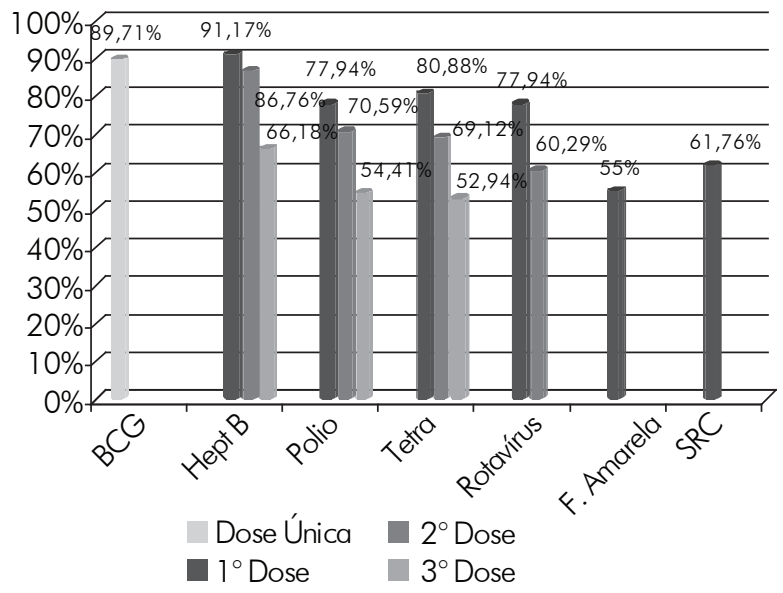

*Fonte: Pesquisa de campo, 2012.

Administraram-se 61 doses da vacina BCG (89,71\%) em recém-nascidos, vale salientar que a meta preconizada pelo PNI é de $90 \%$. Este aumento pode ter ocorrido devido à maior proporção de crianças vacinadas com a BCG nos primeiros dias de vida, quando ainda encontravam-se na maternidade [8].

Foram administradas 62 doses contra Hepatite B (91,17\%). Nas crianças com um mês de vida, aplicaram-se 59 doses $(86,76 \%)$ e para completar o esquema vacinal aos 6 meses foram administradas 45 doses, o que corresponde a 66,18\%. O PNI preconiza $95 \%$ de cobertura vacinal, percebe-se, então, um significativo decréscimo.

A análise do gráfico da vacina contra Hepatite B se explica pelo fato de algumas maternidades aplicarem a primeira dose da vacina quando os recém-nascidos ainda se encontram na maternidade, enquanto que a segunda dose, quando náo administrada aos 2 meses, atrasa a dose aplicada aos 6 meses, o que possibilita em um não cumprimento de intervalos corretos [9].

A primeira dose da vacina poliomielite obteve 53 aplicaçôes $(77,94 \%)$. Logo em seguida, na segunda dose, houve 48 aplicaçóes (70,59\%) e, dando continuidade ao esquema, na terceira dose 37 crianças foram vacinadas, atingindo um percentual de 54,41, havendo desta maneira um decréscimo do $2^{\circ}$ mês e $6^{\circ}$ mês.

A tetravalente obteve 55 doses aplicadas até o segundo mês de vida da criança $(80,88 \%)$, no quarto mês, 47 doses o que representa $69,12 \%$ e, no sexto mês, constataram-se apenas 36 doses (52,94\%). Este resultado comprova decréscimo.

A vacina tetravalente foi a que representou maior número de notificaçóes de efeitos adversos pós-vacinal, tais como febre, eritema, irritabilidade e episódios hipotônicos, o que faz com que as mães fiquem receosas para aplicar as doses subsequentes [10].

Os resultados obtidos com a vacina contra o rotavirus demonstram que na primeira dose houve 53 crianças vacinadas $(77,94 \%)$, já a segunda dose apresentou 41 crianças vacinadas, compondo um percentual de 60,29.

A vacina rotavírus deve ser aplicada: a primeira dose com 1 mês e 15 dias a 3 meses e 7 dias e a segunda dose de 3 meses e sete dias a 5 meses e 15 dias. Estas datas muito criteriosas levam, muitos dos casos, ao náo cumprimento dos prazos estabelecidos [11].

Segundo a Secretária de Vigilância em Saúde, a vacina contra febre amarela é recomendada no estado da Bahia por esta ser uma regiáo endêmica e de transição, o percentual de cobertura vacinal foi de $50 \%$, isto é, das 68 crianças apenas 34 foram vacinadas.

A SRC, que é aplicada no primeiro ano de vida, contemplou 42 doses (61,76\%), um índice muito inferior por se tratar de uma vacina com dose única.

Tanto a febre amarela quanto a SRC tiveram baixo índice de cobertura vacinal, o fato de as mães já terem retomado às suas atividades e com isso deixam de estar atentas ao calendário básico de vacinação da criança [1].

A maior cobertura é alcançada pela BCG e hepatite $B$ por serem vacinas que são aplicadas ainda na maternidade. A cobertura contra a poliomielite e tetravalente são semelhantes e ficam abaixo de $90 \%$, seguida pela cobertura contra a febre Amarela, rotavírus e SRC, que não chegam a atingir nem $80 \%$. A situação vacinal é considerada insatisfatória, podendo incidir a ocorrência de surtos e epidemias sempre que houver circulação dos agentes infecciosos na população.

Quanto maior o nível de escolaridade dos pais, melhores são as formas de medidas de prevenção. 
Essas medidas baseiam-se em cuidados domésticos, conhecimento dos problemas de saúde da criança, e maior uso do serviço de saúde. A falta de conhecimento dos cuidadores demonstra também um déficit de esclarecimento das informaçóes prestadas na sala de vacina, ocorrendo, então, um alto índice de vacinas em atrasos ou até mesmo a não aplicação delas [12].

Vale salientar que este estudo analisou a situação vacinal da Unidade de Saúde da Família Campo Limpo III, mas não foi possível deduzir sobre a qualidade do serviço disponível no município.

É de grande importância a prática educativa e informativa da equipe de enfermagem, a qual, dentre outras funçóes, deve tornar o diálogo com a comunidade esclarecedora, tornando, desta forma, os responsáveis das crianças colaboradores no processo de vacinação. $\mathrm{O}$ cartão-controle e cartão-sombra da ESF devem estar plenamente organizados para possibilitar a existência de informaçóes e dados de boa qualidade.

O presente estudo não pode revelar que a situação vacinal entre crianças de classe social menos favorecida está compatível com a população de uma classe social mais elevada por náo dispormos de informaçóes sobre a real situação vacinal em bairros de classe considerada alta, somente estudos posteriores poderão confirmar essa hipótese.

A partir da análise dos dados levantados, pode-se concluir que nenhuma das vacinas alcançou a meta estabelecida pelo PNI, com ressalva da BCG, que obteve uma cobertura ideal.

Verificou-se que muitos dos responsáveis pelas crianças náo se atentam a data correta da vacinaçáo, atrasando as subsequentes. Notou-se também que as vacinas dadas nos primeiros meses de vida foram as que tiveram maior índice de vacinação, isso, acredita-se que se dá pelo fato de as mães ainda estarem se dedicando exclusivamente ao seu filho.

É possível que os efeitos vacinais adversos causados pela tetravalente pode ter contribuído para uma não aceitação da vacina. As vacinas contra poliomielite, tetravalente e rotavírus tiveram índices bem parecidos por motivo de serem aplicadas juntas, o que faz com que não perca oportunidades de aplicar as vacinas.

As vacinas dadas aos nove meses (Febre amarela) e um ano de vida (Tríplice viral) foram as que tiveram menor percentual de cobertura vacinal, visto que nessa fase as mães já voltaram às atividades anteriores e podem não estar atentas a data correta da aplicação.

A identificação da cobertura vacinal e dos fatores responsáveis pelo retardo ou pela falta de imunizaçooes é ação fundamental para a adequada monitorização dos programas de vacinação e para que haja a identificação das crianças que não foram vacinadas. É de grande relevância que o calendário seja obedecido criteriosamente para que o percentual de cobertura vacinal seja atingido de forma correta, garantindo, assim, uma melhor proteção para criança e um bloqueio na cadeia de transmissão de doenças.

\section{Conclusão}

É de suma importância que a enfermagem realize atividades educativas, a fim de incentivar os cuidadores à observação das datas corretas de vacinação, visando uma prevenção verdadeiramente efetiva. Também se faz necessário gerenciar a sala de vacina para que atividades como armazenamento, controle da temperatura, prazo de validade, preenchimento correto do cartáo-controle, verificaçáo dos faltosos do dia e capacitação dos agentes comunitários de saúde possam obter um melhor acompanhamento das crianças que náo foram vacinadas e com isso fazer busca ativa junto a ACS.

Espera-se que este trabalho possa contribuir para identificação dos verdadeiros fatores da baixa cobertura vacinal no bairro Campo Limpo e que os resultados obtidos possam ajudar a ESF a buscar novas estratégias de busca dessas crianças expostas a fim de evitar graves consequências à saúde.

\section{Referências}

1. Lima TC, Garcia IF, Silva SLE, Souza RBV. Levantamento e análise da condição vacinal de crianças institucionalizadas de 7 a 16 anos. Pediatr Mod 2007;43(6):290-300.

2. Temporão JG. O programa Nacional de Imunização (PNI): origens desenvolvimento. Hist Cienc Saúde-Manguinhos 2003(10):601-17.

3. Brasil. Ministério da saúde. Imunizaçôes coberturas notas técnicas. Datasus: Rio Janeiro. 2011.

4. Aranda MS. Manual de procedimentos para vacinação. 4a ed. Brasília: Ministério da Saúde; 2001. 279 p.

5. Brasil. Ministério da Saúde. Secretaria de Vigilância em Saúde. Departamento de Vigilância Epidemiológica. Doenças Infecciosas e Parasitárias: guia de bolso. 8 a. ed. Brasília: Ministério da Saúde; 2010.448 p.

6. Gil AC. Como elaborar projeto de pesquisa. 5.ed. São Paulo: Attlas; 2010.152p. 
7. Polit DF, Hungler BP. Fundamentos da pesquisa em enfermagem. 3a. ed. Porto Alegre: Artes Médicas; 1995. p. 488.

8. Gattás VL. Avaliação da cobertura vacinal e do uso de serviço para vacinação na regiáo do sudoeste São Paulo, 1989-1990 [Dissertação]. São Paulo: Faculdade de Saúde Pública; 1996.176 p.

9. Souza AP. Perfil da cobertura vacinal das crianças na faixa etária de 0 a 1 ano de idade no município de Pesqueira/ PE entre os anos de 2007 a 2009. Recife: Especialização em Gestão de Sistemas e Serviços de Saúde; 2010. p.27.
10. Vicari CF. Eventos adversos pós-vacinação em crianças no estado de Santa Catarina [Monografia]. Florianópolis: UFSC; 2008. 48p.

11. Hayakawa APS, Sadowski RA, Fernandes MIM. Histórico sobre a vacina contra rotavírus. Uningá Review 2010;5(14):34-9.

12. Silva AAM, Gomes UA, Tonial SR, Silva RA. Cobertura vacinal e fatores de risco associados a não vacinação em localidade urbana do Nordeste brasileiro, 1994. Rev Saúde Pública 1999; 33(2):147-56. 